\title{
Las milicias de segunda línea en la retaguardia franquista. El caso de Galicia*
}

\author{
Julio Prada Rodríguez \\ Universidad de Vigo \\ Djprada@uvigo.es
}

Recibido: $17 / 09 / 2009$

Aceptado: 24/02/2011

\section{RESUMEN}

En este artículo se estudia el papel desempeñado por las milicias de segunda línea en la retaguardia gallega durante la guerra civil. Se destaca, en primer lugar, la proliferación de estas unidades en la zona sublevada y se analizan sus funciones y sus analogías y diferencias con las tradicionales uniones cívicas surgidas para hacer frente a la amenaza revolucionaria. A continuación, se indaga en la composición sociológica de sus miembros, en su implicación en la represión y la delación y en su utilidad para la generación de lealtades compulsivas. Finalmente, se subraya su utilización por parte de sectores sociales comprometidos con la experiencia republicana como refugio para intentar permanecer a salvo de la violencia desatada en la retaguardia.

Palabras clave: Milicias de segunda línea, retaguardia, franquismo, represión, consenso.

\section{The Militias Rearguard in Pro-Franco Spain. The Example of Galicia}

\begin{abstract}
This article explores the role played by the militias of volunteers in the Galician rearguard during the civil war. We emphasize, initially, the proliferation of these militias and we analyze their functions and their analogies and differences with the traditional civic unions born to fight against the revolutionary threat. Next, we investigate the sociological composition of its members, their involvement in repression and denunciation, and its usefulness for the generation of compulsive loyalties. Finally, we affirmed their utilization by supporters of the Republic to try to remain safe from the violence.
\end{abstract}

Key words: Militias rearguard, rearguard, Franco's regime, repression, consensus.

Sumario: 1. La proliferación de milicias de segunda línea en la zona rebelde. 2. Los cívicos. 3. “...buscando seguro refugio, dadas las actuales circunstancias". 4. Conclusión.

${ }^{*}$ Este artículo se inscribe en las líneas de investigación abiertas en el seno de los Proyectos Ref. HAR2010-15857 y 10SEC382035PR, de los que el autor es investigador principal. 
El papel desempeñado por las milicias de voluntarios en el bando franquista durante la guerra civil española cuenta ya con un buen número de aproximaciones, comenzando por el clásico estudio de R. Casas de la Vega ${ }^{1}$. En particular, se ha destacado el hecho de que la incorporación a las columnas militares de un crecido número de civiles en ambos bandos resultó determinante para que aquella contienda no quedase circunscrita a un enfrentamiento tradicional entre dos ejércitos fraccionados y adquiriese una notable dimensión "popular"2. Bastante más escasos son los trabajos que se detienen a analizar en profundidad todo lo que gira en torno a las denominadas "milicias de segunda línea" en la retaguardia rebelde; no tanto las adscritas a una organización matriz, caso de Falange Española (FE), la Comunión Tradicionalista (CT), las Juventudes de Acción Popular (JAP) o las escasamente nutridas de Renovación Española (RE), cuanto esos "elementos cívicos" no integrados en ninguna de ellas hasta que el sable del caudillo forzó su unificación en FET-JONS. Y, sin embargo, su contribución a la victoria de los sublevados y a la implantación del "nuevo" orden político y social que acompaña al lento proceso de institucionalización del régimen resultó, como veremos, fundamental en numerosos ámbitos.

\section{La proliferación de milicias de segunda línea en la zona rebelde}

Los trabajos sobre la sublevación militar y la represión franquista realizados, sobre todo, a partir de los años noventa tienden a subrayar cada vez más la intrincada red de contactos y las relaciones existentes entre elementos civiles y militares con anterioridad al golpe ${ }^{3}$. Ello no obsta para mantener la tesis del carácter esencialmente militar de la conspiración y el papel secundario que aquéllos - los paisanos - tuvieron en la fase anterior al fracaso del golpe de Estado y a su transformación en guerra civil. Y tampoco para seguir insistiendo en la desconfianza que los militares tenían en unas masas populares que, salvo excepciones, no parecían demasiado dispuestas a acudir por decenas de miles a la "llamada de la patria"4. Sólo cuando apremió la urgencia

\footnotetext{
${ }^{1}$ CASAS DE LA VEGA, Rafael: Las milicias nacionales en la guerra de España, Madrid, Editora Nacional, 1977.

${ }^{2}$ ARÓSTEGUI, Julio: "Sociedad y milicias en la Guerra Civil Española, 1936-1939. Una reflexión metodológica", en Estudios de Historia de España. Homenaje a Tuñón de Lara, Madrid, U.I.M.P., 1981, vol. 2, pp. 307-325.

${ }^{3}$ Cfr., por ejemplo, las contribuciones provinciales a la obra colectiva JUANA, Jesús de y PRADA, Julio: Lo que han hecho en Galicia. Violencia política, represión y exilio (1936-1939), Barcelona, Crítica, 2006; MARTÍN JIMÉNEZ, Ignacio: La guerra civil en Valladolid (1936-1939). Amaneceres ensangrentados, Valladolid, Ámbito, 2000, pp. 61 y ss.; CASTRO, Luis: Capital de la Cruzada. Burgos durante la guerra Civil, Barcelona, Crítica, 2006, pp. 2-3; RILOVA PÉREZ, Isaac: Guerra Civil y violencia política en Burgos (1936-1943), Grupo Dossoles Burgos, 2001, p. 67; también ejemplos en diferentes capítulos de BERZAL DE LA ROSA, Enrique (coord.): Testimonio de voces olvidadas, León, Fundación 27 de marzo, 2007; etc.

${ }^{4}$ Los periódicos de toda la retaguardia rebelde están llenos de referencias a la necesidad de multiplicar los contingentes de voluntarios hacia los frentes bélicos, recurriendo con frecuencia a la comparación con aquellas provincias que se mostraban más diligentes en la recluta (cfr., por ejemplo, $\mathrm{La}$ Voz de Galicia, 15/08/1936, p. 2 con relación al poco entusiasmo de los coruñeses frente a navarros,
} 
de enviar carne de cañón a los frentes y al aseguramiento de la retaguardia se unió la necesidad de canalizar todas las voluntades y energías hacia el esfuerzo bélico, sólo entonces hicieron de la necesidad virtud y la propaganda comenzó a disfrazar de alzamiento patriótico lo que no era sino rebelión contra el poder legítimamente constituido.

Fue, en efecto, el fracaso parcial de la sublevación y la propia división del Ejército los que revalorizaron el papel de los civiles, impelidos a desarrollar una ingente movilización capaz de contrarrestar la resistencia articulada en diversas zonas del Estado. La lealtad geográfica, la propia dinámica de los acontecimientos y el ejercicio de una despiadada represión obraron el milagro de convertir los apoyos iniciales, sin duda significativos pero de ningún modo masivos, en una riada que mezclaba en diversas proporciones adhesiones inquebrantables, compromisos apócrifos y ofrecimientos forzados. Pero lo cierto es que esos mismos maridajes y conexiones son los que, en parte, ayudan a explicar la rapidez con la que entusiastas ciudadanos acompañan a las tropas, casi desde la misma proclamación del estado de guerra, en aquellas provincias y regiones en las que los rebeldes se imponen con facilidad.

Así, el 23 de julio de 1936, sólo tres días después de declarado el estado de guerra en Galicia, el comandante retirado al amparo de la Ley Azaña Jesús Teijeiro Pérez comenzó la organización de los Caballeros de la Coruña, siendo su principal impulsor hasta que, a principios de agosto, lo sustituyó el teniente coronel de la Guardia Civil Benito de Haro Lumbreras; exactamente un mes más tarde, los seiscientos milicianos que formaban la Milicia Ciudadana Coruñesa realizaron, a decir de la prensa, su primer y brillante desfile por las calles de la plaza. En Sevilla, el día 24 de julio, Queipo de Llano creaba las Fuerzas Cívicas al Servicio de España, en las que se integraron los derechistas armados durante las jornadas previas que no formaban parte de la Falange o el Requeté; como en el caso anterior, a su frente se pusieron jefes y oficiales retirados que comenzaron a darles instrucción y disciplina ${ }^{5}$. Esa misma jornada, el comandante militar de la plaza de Vitoria, general Ángel García Benítez, dispuso la organización de una milicia que cooperase en la vigilancia y defensa de la capital; tan solo cinco días más tarde, sus primeros afiliados estaban en disposición de prestar servicio y el alcalde de la ciudad pudo declararla oficialmente constituida ${ }^{6}$.

vallisoletanos y aragoneses). Tampoco faltan las referencias irónicas a los milicianos que «ardían en deseos» de combatir en primera línea, pero se encontraban atados por «el molesto deber de las atenciones oficinescas o de vigilancia de la ciudad y de los pueblos» y a pesar de contarse por centenares los ciudadanos de más de treinta y cinco años dispuestos a sustituirlos en tales menesteres (La Región, 7//08/1936)

${ }^{5}$ ORTIZ VILLALBA, Juan: Sevilla 1936: del golpe militar a la guerra civil, Córdoba, Imprenta Vistalegre, 1998, p. 152. En esta capital andaluza también se organizó la Milicia Voluntaria de Caballistas, que tenía como misión auxiliar a la Guardia Civil, participar en la persecución de huidos, colaborar en el desarme de caseríos y pueblos y organizar milicias similares en estos últimos [cfr. BARRIOS, Manuel, El último virrey. (Queipo de Llano), Sevilla, J. Rodríguez Castillejo, S.A., 1990, pp. 132 y ss.].

${ }^{6}$ SEVILLANO CALERO, Francisco: Exterminio. El terror con Franco, Madrid, Oberón Ediciones, 2004, pp. 45-46. 
En Huelva, la Guardia Cívica se organizó el 7 de agosto; inicialmente estuvo integrada por alrededor de trescientas personas dirigidas por dos militares ${ }^{7}$. En Ourense, los primeros Caballeros de Santiago se alistaron ese mismo día 7 de agosto, y aunque la idea de imitar a sus homónimos de A Coruña partió de dos civiles, la organización e instrucción de los mismos corrió a cargo del comandante de Infantería en situación de disponible forzoso Antonio Casar Olavarrieta ${ }^{8}$; en un principio se pretendía organizar ocho compañías, a sumar a las que se formasen en cada una de las diez restantes cabezas de partido, pero pronto las solicitudes acabarían desbordando estas previsiones: en febrero de 1937 el número de inscritos alcanzaba ya los ochocientos, sólo en la capital provincial. En Vigo, los trabajos de organización de la Guardia Cívica estaba previsto que rematasen a mediados de ese mes, fecha en que sus impulsores debían "dar cuenta a las Autoridades Militares del número de inscriptos y de sus condiciones". No le fue a la zaga la vecina ciudad de Pontevedra, donde el teniente de la Benemérita Patiño asumió inicialmente su jefatura, aunque pronto acabaría haciéndose con ella el ex diputado de RE Víctor Lis Quibén ${ }^{10}$. Algo más reticentes parecen haber sido en Ceuta, donde la Comandancia Militar no anunció su creación hasta mediados de ese mes, por cierto que en términos conminatorios, pues, con la afiliación, se trataba también de "comenzar a deducir de una manera clara y terminante quienes están contra nosotros (...) y quienes en contra... No hay más que dos caminos, o con nosotros, o contra nosotros"11. Y los ejemplos podrían multiplicarse por docenas.

La prensa acertaba a describir muy bien sus integrantes como "hombres que, ya por razones de edad, de ocupaciones profesionales o de ciertas vicisitudes de familia, no pueden de una manera permanente formar en las primeras filas de milicias de choque" 12 . Se trataba, en efecto, de encuadrar a todos los que, por no hallarse en condiciones de ingresar en el Ejército ni en las milicias de primera línea, y siendo personas de probados antecedentes, desearan colaborar con las fuerzas de orden público y desempeñar un papel más activo en la retaguardia que el de meros simpatizantes de los golpistas.

Su subordinación a las autoridades militares de cada provincia desde el primer instante del golpe no ofrece duda: ellas son las que bendicen la iniciativa, las que las provén de mandos de confianza y las que reproducen la misma estructura orgánica que conocen del Ejército, organizándose en escuadras, pelotones, secciones y compañías. Las unidades más grandes estaban dirigidas por militares retirados acogidos a la "Ley Azaña", los cuales, por cierto, también jugaron un importante papel en la

${ }^{7}$ ESPINOSA MAESTRE, Francisco: La Guerra Civil en Huelva, Huelva, Diputación Provincial, 1996, p. 493.

${ }^{8}$ Vid. PRADA RODRÍGUEZ, Julio: “ '...En defensa de su Dios y de su patria'. A milicia ourensá dos Caballeros de Santiago", Minius, Vigo, 8, (2000), pp. 165-187.

${ }^{9}$ El Pueblo Gallego, 12/09/1936, p. 3.

${ }^{10}$ FERNÁNDEZ SANTANDER, Carlos: El Alzamiento de 1936 en Galicia. Datos para una historia de la guerra civil, Sada-A Coruña, Ediciós do Castro, 1983', p. 258.

${ }^{11}$ Cit. en SÁNCHEZ MONTOYA, Francisco: Ceuta y el Norte de África. República, Guerra y Represión 1931-1944, Ceuta, Ed. Navítola, 2005, pp. 371-372.

${ }^{12}$ El Pueblo Gallego, 12/09/1936, p. 3. 
fase de la conspiración poniéndose incondicionalmente al servicio de sus compañeros de armas para cuando el golpe se concretase. Además de su lógica utilidad como instructores, dada su formación castrense y experiencia de mando, su extracción social e ideológica conectaba muy bien con ese conglomerado de intereses articulado alrededor de la derecha reaccionaria que confluye en la sublevación militar y del que, en última instancia, también forman parte.

Tales líneas de continuidad son, por ejemplo, claramente perceptibles en el caso de Teruel, donde los oficiales retirados se unieron en una "asociación" con la intención de mantenerse en comunicación, extendiendo sus contactos a elementos civiles; la Acción Ciudadana turolense se configuró como un órgano militarizado, supuestamente apolítico, que tenía como principales objetivos "la protección del orden público, de las personas y de la propiedad, tan amenazadas en Zaragoza por las huelgas del período republicano". Consumado el golpe, sus miembros fueron clasificados en tres grupos o líneas según estuvieran o no en el frente y fueran mayores o menores de treinta y cinco años, con la misión de "ser retaguardia del Ejército en la obra de pacificación de la España que deseamos"13. Algo parecido ocurre en Ourense, donde el máximo responsable de los Caballeros, A. Casar Olavarrieta, procedía de una de esas familias que tan bien ejemplifican el proceso de articulación de la derecha reaccionaria en España: hijo del general retirado Celso Casar Blanco - acaudalado propietario que había sido miembro del comité maurista provincial, de la Unión Patriótica, vicepresidente de la Diputación Provincial en tiempos del general Primo de Rivera y presidente del comité local de la Unión Monárquica Nacional-, ex candidato a Cortes por el Partido Radical, activo conspirador y uno de los hombres clave en la toma del Gobierno Civil por los militares rebeldes el 20 de julio de 1936.

No obstante, aunque no se nos ocultan ciertas similitudes, no parece que puedan asimilarse sin más a aquellas uniones cívicas que habían surgido al rebufo de la marea revolucionaria de 1917 en un intento de coadyuvar a mantener el orden social amenazado. Estas últimas habían sido una respuesta en gran parte espontánea de los sectores propietarios que buscaba salvaguardar sus intereses económicos y el marco de relaciones sociales imperante, por más que "algunos de sus postulados teóricos y prácticos serían llevados hasta las últimas consecuencias por cierta derecha radical o contrarrevolucionaria en los años subsiguientes"14. No cabe duda que en las regiones en las que el golpe se impuso con facilidad existe una corriente instintiva de apoyo a los rebeldes que se manifiesta en los miles de ciudadanos que acuden a los cuarteles, comandancias militares y delegaciones de orden público a ponerse a disposición de los militares antes que la despiadada represión pueda ser esgrimida como argumento justificativo de tales entusiasmos; tampoco de que quienes así actúan son muy conscientes de que la seguridad de sus haciendas y utilidades se encuentra mejor garantizada con aquéllos que en "zona roja". Las fuentes orales permiten entreverlo con claridad:

${ }^{13}$ CENARRO LAGUNAS, Ángela: El fin de la esperanza: Fascismo y Guerra Civil en la provincia de Teruel (1936-1939), Teruel, Instituto de Estudios Turolenses, 1996, p. 63.

${ }^{14}$ GONZÁLEZ CALLEJA, Eduardo y del REY REGUILLO, Fernando: La defensa armada contra la revolución. Una historia de las guardias cívicas en la España del siglo XX, Madrid, CSIC, 1995, p. 19. 


\begin{abstract}
“Aquello fue una vorágine, una cosa desmedida. Allí estaba medio Ourense para hacerse Caballero de Santiago. Una cosa nunca vista. Los había que no podían levantar un fusil, pero todos se veían arrastrados por un entusiasmo fuera de toda lógica. Se pensaba que la guerra era cosa de días y todos querían contribuir de una manera $u$ otra... Incluso los que siempre habían estado alejados de la política dejaban atrás cualquier duda y entraban en aquella locura" ${ }^{15}$.
\end{abstract}

Por otro lado, mientras las milicias armadas asociadas a una formación política concreta dependen de ella orgánica e ideológicamente y aspiran a la conquista del Estado, a los cívicos no parece haberles preocupado la teorización política y carecían de cualquier veleidad no ya de asaltar el poder, sino de influir en un sentido u otro la orientación política del futuro régimen. Incluso, si uno es capaz de abstraerse a la propaganda que puebla las páginas de los periódicos de la España sublevada, comprobará que detrás de esas manifestaciones de apoyo ciudadano hay menos de "espontáneo" de lo que aquéllos aseguran y los propios protagonistas percibieron en su día. En un contexto en el que el aseguramiento de la retaguardia y la movilización a favor del bando rebelde eran una necesidad ineludible para atender las necesidades bélicas y posibilitar la institucionalización del régimen, era preciso apostar por experiencias de carácter integrador de las "masas" que garantizasen su participación a través de estructuras organizativas disciplinadas que facilitasen su control.

En consecuencia, su creación también responde a una determinada concepción del Estado y de la política en la que la uniformización del cuerpo social se impone sobre la idea liberal del individuo como ser libre y autodeterminado. Nadie mejor, por tanto, que esos militares - a fin de cuentas conspicuos representantes del mismo establishment que su acción redentora pretendía salvaguardar - que invariablemente asumieron su organización para representarlas, garantizar su teórico "apoliticismo" y revestirlas de la "espontaneidad" y el "patriotismo" necesario. Por eso, se los configuró como elementos meramente auxiliares del Ejército y de la Guardia Civil, aunque, de acuerdo con la Orden General de la Milicia Española, sus integrantes tuviesen funciones de policía gubernativa y, cuando prestasen servicio, asumiesen la consideración de fuerza armada a todos los efectos; incluido el hecho de que cualquier acto de resistencia o agresión contra ellos significaba la inmediata incoación de un sumario sujeto a las reglas inspiradoras del procedimiento militar.

\title{
2. Los cívicos
}

Pero, ¿cuáles fueron las misiones y cuál era la extracción sociológica de esos cívicos que brotaron por doquier en aquel verano del treinta y seis? Los responsables de aquellos precoces Caballeros de la Coruña que habíamos visto nacer sólo tres días después de consumado el golpe, les atribuían la misión de

\footnotetext{
${ }^{15}$ Testimonio de J.F.O.V., recogido en febrero de 1999 (traducción del gallego).
} 
"coadyuvar con la tropa en la represión y pacificación de las zonas de la provincia (...) atacadas por los elementos subversivos (...) [y] ser la base de una organización militar de elementos civiles que, por su espíritu, han de tener la gloriosa misión de restaurar los valores nacionales (...)"16.

Sus homónimos de Ourense portaban una identificación, a modo de cédula de identidad, en la que figuraba, entre otras, la obligación que adquirían sus portadores de

"Defender el orden público, ejerciendo funciones de la Policía en todo momento (...), auxiliar a la fuerza pública cuando ésta lo necesite [y] sustituirla en todos los servicios que ésta tenga que prestar cuando lo ordene el Mando (...)"17.

La tríada de funciones que se desprende de los párrafos anteriores está, en efecto, detrás de la organización de estas milicias en toda la España sublevada. En primer lugar, se trataba de colaborar con los contingentes militares en el sometimiento de los diversos núcleos de resistencia al golpe que pudieran haberse organizado en diferentes localidades de cada provincia. Obviamente, esta finalidad sólo tenía sentido en lugares en los que aquéllos hubieron de enfrontar alguna oposición y ésta tuvo cierta continuidad en el tiempo, pues donde los rebeldes se impusieron sin dificultad en las primeras horas ni siquiera hubo plazo para poder instituirlas y la colaboración de los civiles no encuadrados en alguna de las organizaciones que lo secundaron tuvo un carácter más espontáneo y menos formalizado.

Dominados aquéllos, su misión esencial consistió en auxiliar a las fuerzas del orden en la salvaguarda de la paz ciudadana y la tranquilidad pública en el interior de cada población de la retaguardia en la que se organizaban y en su extrarradio. No obstante, llegado el caso, "el espíritu patriótico que alienta en cada Guardia Cívico, lo llevará (...) a los lugares o a los cometidos de máximo peligro y responsabilidad" 18 , pues su mayor honra era hacer efectiva su divisa de acudir dónde fueran llamados por el mando "en defensa de su Dios y de su Patria". Ello significó no sólo ejercer propiamente funciones de policía sino implicarse directamente en la represión, como demuestra su participación en numerosos paseos en lugares tan distantes como Sevilla ${ }^{19}$ o Zarago$\mathrm{za}^{20}$. En Galicia la diversidad de situaciones parece haber sido la nota dominante en esta espinosa materia: la participación personal de miembros de los Caballeros de la Coru$\tilde{n} a$ y de la Guardia Cívica pontevedresa en los asesinatos extrajudiciales perpetrados

${ }^{16}$ Cit. en ARTIAGA, Aurora: “ ‘Todo por España y para Dios'. A Bandera Legionaria Gallega de Falange Española na Guerra Civil”, en X. L. Axeitos, E. Grandío y R. Villares (eds.), A Patria enteira. Homenaxe a Xosé Ramón Barreiro Fernández, Santiago de Compostela, C.C.G.-R.A.G.-Servicio de Publicaciones de la Universidad de Santiago de Compostela, 2008, p. 23.

${ }^{17}$ Reverso de la identificación del caballero J.P.L., en Archivo Histórico Provincial de Ourense (AHPOU), Fondo Diputación.

${ }^{18}$ El Pueblo Gallego, 12/09/1936, p. 3.

${ }^{19}$ ORTIZ VILLALBA, Juan: Sevilla $1936 \ldots$, op. cit., p. 153.

${ }^{20}$ CIFUENTES CHUECA, Julita: "El ocaso de la República y los orígenes del nuevo orden en la provincia de Zaragoza", en J. Casanova et al., El pasado oculto. Fascismo y violencia en Aragón (19361939), Zaragoza, Mira Editores S.A., 1999, p. 101. 
en ambas capitales no parece ofrecer dudas ${ }^{21}$; por el contrario, en Ourense se los tenía por moderados ${ }^{22}$ y no faltan testimonios orales y pruebas documentales que certifican la predisposición de algunos de sus afiliados a intervenir en defensa de ciudadanos sometidos a los desmanes de falangistas. Algo parecido parece haber ocurrido en Huelva, donde, a juicio de F. Espinosa, procuraron no verse envueltos en la represión desatada, aunque se vieron obligados a participar en registros y detenciones e, incluso, en la conducción de prisioneros al paredón ${ }^{23}$.

La delación constituía también parte esencial de su misión. Ingresar en cualquier guardia cívica significaba aceptar el papel de diligente informador de cuanto acontecía en su entorno; convertirse en un atento escrutador de todos sus vecinos sospechosos de connivencias izquierdistas. El crecido número de asociados que estas organizaciones consiguieron reclutar, su amplia extracción social y el hecho de no hubiese manzana ni barrio de las ciudades y villas en las que proliferaron que no contase con varios integrantes dispuestos a señalar con el dedo, hicieron de ellos principalísimos confidentes de las más diversas instancias represivas. Como para tantos, denunciar a sus vecinos fue su "primer acto político de compromiso con la dictadura"24.

Y no sólo a sus vecinos. El detallado análisis de la composición de las diferentes escuadras en que operaban los Caballeros de Santiago nos ha permitido comprobar que, en algunos casos, la distribución de efectivos funcionaba como un mecanismo más de control sobre los cívicos sospechosos. Resulta imposible determinar si ésta fue una práctica generalizada y sistemática o solo ocasional; si formaba parte de una estrategia perfectamente meditada o respondía sólo a supuestos excepcionales de carácter individual. Lo que no ofrece dudas es el hecho de que ciertos responsables de sección y de pelotón emplearon a cabos y a milicianos de su confianza para vigilar la conducta de los caballeros de "pasado dudoso" que formaban parte de su escuadra. Todo parece indicar que estas observaciones eran transmitidas de manera verbal a los oficiales responsables del servicio, los cuales las utilizaban para elaborar informes de conducta que iban a parar a las diversas instancias encargadas de fiscalizar la conducta pública y privada del miliciano en cuestión. Sirva como ejemplo el siguiente:

${ }^{21}$ Cfr. el testimonio de un evadido perteneciente al Sindicato del Transporte Marítimo de CNT, que acusa a los coruñeses de «buscar a los ciudadanos y sus familias para saciar sus intentos (sic) criminales y probocar (sic) situaciones de violencia para justificar las matanzas de los pueblos y de la ciudad Herculina» (Archivo Histórico Nacional, Sección Guerra Civil, PS Bilbao, Carp. 259, exp. 21);Vid., asimismo, LAMELA GARCÍA, V. Luis: A Coruña, 1936. Memoria convulsa de una represión, Sada-A Coruña, Ediciós do Castro, 2002, pp. 33, 41, 265. Con respecto a los pontevedreses, vid, VV.AA.: Os mártires do 36, Vigo, Promocións Culturais Galegas, S.A., 1996. Estos últimos también participaron en la ejecución de hombres y mujeres condenados a muerte en consejos sumarísimos y no sólo en los clásicos paseos, como la propia prensa recoge sin el más mínimo pudor (vid. Diario de Pontevedra, 14/12/1936, p. 2).

${ }^{22}$ ALONSO RÍOS, Antón: O siñor Afranio. Ou como me rispei das gadoupas da morte. (Memorias dun fuxido), Vigo, Castrelos, 1979, p. 172.

${ }^{23}$ ESPINOSA MAESTRE, Francisco: La Guerra Civil en Huelva ..., op. cit., p. 493, n. 74.

${ }^{24}$ CASANOVA, Julián: "Una dictadura de cuarenta años", en J. Casanova (coord.), Morir, matar, sobrevivir. La violencia en la dictadura de Franco, Barcelona, Crítica, 2002, p. 32. 
"En su escrito del próximo pasado día 9, el oficial-inspector de las milicias de segunda línea Caballeros de Santiago me dice lo siguiente: 'Encargado (sic) por este oficial-inspector la atenta vigilancia de la conducta observada por el miliciano de segunda linea (sic) D. F.M.G., resulta que se muestra en sus manifestaciones entusiasta partidario del G.M.N., aplaudiendo las victorias del invicto Ejército español. Cumple con puntualidad el servicio a su cargo y nada hay en su conducta pública o privada que desmerezca el buen concepto en que lo tienen sus jefes. Pertenecía como simple socio al Partido de Azaña del que se apartó después de las pasadas elecciones. Se le considera de orden y afecto al actual Movimiento, para el que ha contribuido generosamente en todas las suscriciones (sic) abiertas (...)'. Lo que tengo a bien trasladar a S.E. para los efectos oportunos" 25 .

El destino final de estos informes era muy variado. Posiblemente su mayoría tuvieran un carácter esencialmente interno; es decir, estuvieran destinados sólo a garantizar que en el mencionado Batallón figuraran sólo elementos de probada fidelidad al régimen. Así, en el caso anterior, no nos consta que contra la persona informada se incoase procedimiento sumarial alguno, que figurara entre los presos gubernativos o tuviera o solicitara algún empleo oficial, razones que justificarían la elaboración de un documento como el citado. En otros casos, sin embargo, estos informes, además de determinar una sanción de carácter interno, acababan en manos de la jurisdicción castrense, como ocurrió con el militante socialista D.F.F., a quien se calificaba de "principal agitador de las masas obreras, haciendo entusiasta propaganda del Frente Popular entre sus convecinos"; finalizado el proceso de depuración, fue expulsado de la organización el día 24 de febrero de 1937 y sólo tres semanas más tarde fue detenido e inculpado en una causa incoada por el juez militar de la plaza durante la cual salieron a relucir sus antecedentes, incluida su proscripción de las milicias de segunda línea.

La tercera de esas funciones fundamentales tiene que ver con todo el entramado propagandístico del régimen, con su necesidad de ampliar los apoyos sociales con los que contaba y con su contribución a esa "misión de restaurar los valores nacionales". En primer término, la cobertura informativa de la prensa y la radio, los desfiles, los rituales alrededor de su constitución y de las virtudes que debían adornarlos y la difusión y glorificación de las acciones en las que tomaron parte contribuyeron a amplificar la sensación de apoyo ciudadano y popular a la sublevación. De este modo, también colaboraron a la exaltación guerrera y a la mística emocional propia de aquellos momentos en los que todos los “buenos patriotas" debían laborar, cada uno desde su puesto, a la victoria de esos nuevos cruzados que inundaban los campos de batalla.

Y no menos fundamentales fueron a la hora de favorecer la generación de lealtades compulsivas a través de la movilización de los afectos y la captación de tibios, pasivos e indiferentes. La favorable respuesta que la sublevación tuvo en importantes segmentos de la sociedad tenía que ser canalizada no sólo para aprestar a quienes les

${ }^{25}$ Informe de conducta remitido al Comisario de Investigación y Vigilancia de Ourense por el Inspector-jefe del mismo Cuerpo con fecha 13/01/1937 [Archivo de la Comisaría de Investigación y Vigilancia de Ourense (ACO), expediente $\mathrm{s} / \mathrm{n}^{\mathrm{o}}$. 
apoyaban e incitaban, sino también para provocar un efecto aluvión sobre otros sectores de la población más reticentes a comprometerse activamente. Los que se movían en los confusos aledaños de la indiferencia se sentían impelidos, por la sugestión que sobre sus conciencias ejercía la multitud-masa, a participar en este ensayo de acoger bajo una misma bandera a todos cuantos se identificaban con los postulados de la nueva cruzada.

A esas tres misiones esenciales comentadas en los párrafos precedentes, enseguida añadieron otras de menor significación y enjundia como vigilancia nocturna, inspección de locales, custodia de edificios oficiales, escolta y protección de personalidades y convoyes, patrulla de carreteras, colaboración en la recaudación de las más diversas suscripciones patrióticas, censo escolar, asistencia a misas de campaña, desfiles oficiales y demás actos de propaganda, recepción, despacho, conducción y entrega de paquetes, encargos y correspondencia en los frentes de batalla - las denominadas "Expediciones Postales"-, censores de Correos y Telégrafos, etc.

La extracción sociológica de estos milicianos depende, lógicamente, de las características del entorno geográfico en el que fueron reclutados. El primer requisito al que ya se ha aludido era que se tratase de varones con edades comprendidas entre los treinta y los sesenta años que no se hallasen en disposición de acudir a los frentes de guerra. Aunque la mayoría de las ordenanzas fijaban estos límites, no cabe duda que se interpretaron con cierta flexibilidad: veintiséis miembros de los Caballeros de Santiago identificados (el 3,01\%) no habían ingresado aún en la treintena —en varios casos nos consta que se trata de jóvenes que fueron declarados exentos del servicio militar por alguna deficiencia física y que, no obstante, fueron admitidos como milicianos de segunda línea-, mientras que ocho (el 0,93\%) superaban la barrera teórica de los sesenta años.

En cuanto a su estructura socioprofesional, la prensa insiste con frecuencia en el hecho de que en las milicias se encuentran hermanadas todas las clases y profesiones. Así, aseguraba que entre los miembros de la Milicia Ciudadana de A Coruña abundaban "médicos, abogados, odontólogos, industriales, comerciantes, propietarios, oficinistas, empleados, etc." ${ }^{.26}$. Sin embargo, sólo cuando disponemos de listados nominativos o de fichas que contienen la profesión y el domicilio de los milicianos podemos determinar con precisión la veracidad o no de tales afirmaciones. Así, por ejemplo, del total de milicianos y aspirantes a ingresar en el Batallón de Caballeros de Santiago radicados en el ayuntamiento de Ourense conocemos la profesión de 642 $(53,32 \%)$ y el domicilio de $1.018(84,55 \%)$ gracias a su cruce con los datos del censo electoral de 1934. La extracción profesional refleja, como es lógico, el carácter marcadamente urbano de esta milicia: sólo el $14,80 \%$ del total consta como labradores, jornaleros o braceros, e incluso esta cifra debería ser corregida a la baja, pues entre quienes declaran como ocupación principal la de "jornaleros" figuran trabajadores a tiempo parcial en la construcción o en otras labores no agrícolas.

Las ocupaciones relacionadas con la industria y la construcción (albañiles, peones, canteros, obreros y capataces) aportan en conjunto un $4,83 \%$, cifra también muy re-

${ }^{26}$ Cit. en ARTIAGA, Aurora: “ ‘Todo por España y para Dios'...”, op. cit., p. 25. 
ducida incluso para una ciudad de las características del Ourense de la segunda mitad de los años treinta. Consideradas en su conjunto las profesiones urbanas relacionadas con la prestación de servicios y la alimentación (pintores, carpinteros, electricistas, mecánicos, herreros y similares; relojeros; sastres y zapateros; chóferes, barberos, camareros, panaderos, taberneros y similares) representan el 22,74\% (146 registros), mientras que las más directamente relacionadas con el comercio (dependientes, empleados, comisionistas, viajantes, representantes y agentes comerciales) se elevan a 100 casos $(15,58 \%)$. La elite local, formada por comerciantes, industriales, almacenistas, propietarios y contratistas, resulta, con 122 casos (19\%), el segundo grupo más numeroso; un porcentaje muy elevado si tenemos en cuenta su participación en el conjunto de la estructura ocupacional del municipio. Las profesiones liberales, los tipógrafos y los ingenieros se sitúan en el 6,23\% (40 registros), mientras que los empleados públicos y funcionarios - excepto los maestros, profesores y catedráticos, que representan el 1,87\% del total conocido- se elevan al 9,19\%. Estudiantes, militares y miembros de las fuerzas de seguridad y el grupo de "otros" aportan cantidades muy inferiores.

Por tanto, resulta evidente el peso de los sectores urbanos en la composición de los Caballeros de Santiago, y muy especialmente el de los elementos más representativos de las denominadas "gentes de orden": la elite local y aquellos individuos que por razones laborales dependen de ésta. También debemos destacar la importancia del conjunto del sector público - habida cuenta su reducida participación en el global de la estructura ocupacional-, lo que, en parte, está relacionado con la necesidad de acreditar una conducta sin tacha que les permitiese conservar el puesto ante las sucesivas depuraciones practicadas por los sublevados; asimismo, cuando se trata de funcionarios de nueva incorporación, parece haber prevalecido el deseo de mostrar su colaboración y agradecimiento con el régimen contribuyendo a la conservación del orden.

Este análisis no es exactamente coincidente si analizamos las secciones de $\mathrm{Ca}$ balleros de Santiago reclutadas en las principales villas de la provincia como Verín, Canedo, Carballiño, Ribadavia, Xinzo de Limia, A Rúa, O Barco de Valdeorras, etc. A diferencia del municipio capitalino, resulta imposible cuantificar exactamente el número de sus integrantes al no poder contar con listados nominativos completos. Con todo, los 380 casos identificados permiten aventurar algunas diferencias significativas en lo que respecta a su estructura socioprofesional, toda vez que la composición por edades no ofrece contrastes dignos de mención como no sea el de un mayor peso de los grupos intermedios (por lo demás coherente con el mayor índice de envejecimiento del campo como consecuencia de los efectos de la emigración y el éxodo rural).

Así, labradores y jornaleros pasan a ocupar el primer puesto con un $35,07 \%$ frente al $14,80 \%$ que representaban en el ayuntamiento orensano. Se incrementa, asimismo, el porcentaje de los procedentes del sector de la construcción $(10,41 \%$ frente a $4,83 \%)$, los maestros $(2,46 \%$ frente a $1,87 \%)$ y el grupo de "otros" $(6,30 \%$ frente a $5,75 \%)$; descienden, por el contrario, los grupos de servicios $(13,15 \%-22,74 \%$ y 
$8,22 \%-15,58 \%)$, el de comerciantes y propietarios (17,81\%-19\%), las profesiones liberales $(2,19 \%-6,23 \%)$ y los funcionarios $(4,38 \%-9,19 \%)$.

Estas cifras vienen a confirmar que el campesinado se mostró más reticente a encuadrarse en las milicias de segunda línea, toda vez que el considerable incremento de los grupos vinculados al sector primario está muy lejos del peso real que éstos tenían en la economía rural y en las villas orensanas de la segunda mitad de los años treinta. El hecho de que incluso dentro de un ayuntamiento sean mayoría los que viven en los núcleos más poblados - y particularmente en la capital municipalapunta en esa misma dirección; algo que, por otra parte, resulta lógico, pues en las mayores concentraciones demográficas es donde, a priori, cabía aguardar mayores alteraciones del orden. En todo caso, en los ayuntamientos próximos a las sierras y montes en los que había importantes concentraciones de huidos, las tareas de control del orden público tenían que ampliarse a distancias bastante lejanas, actuando en este caso como elementos que reforzaban a los contingentes de guardias civiles y carabineros, sin que fuese tan frecuente la prestación de servicios en solitario.

\section{3. "...buscando seguro refugio, dadas las actuales circunstancias"}

Los impulsores de la Guardia Cívica de Vigo aseguraban públicamente que la organización no admitía en su seno a

"hombres procedentes de sectas o de partidos políticos que, lejos de poseer sentimientos patrióticos, se han producido activamente o con el peso de sus votos contra la unidad de la patria o del espíritu católico español”27.

También Defensa Ciudadana de Badajoz aseguraba ser una organización apolítica, "porque equivale a decir que es pura, que está libre de esas contaminaciones de todo género que trae aparejadas la política, que corroe como una carcoma infernal los más fuertes puntales de la ciudadanía" 28 . Sin embargo, la propia prensa rebelde, en las más diversas capitales, se empeña en desmentir la realidad de tales extremos. Periódicamente, sus páginas daban cuenta de la expulsión de algún afiliado de pasado extremista que había logrado infiltrarse en tal o cual milicia, pero que, al final, no había podido superar los sucesivos filtros que, con el paso de los meses, habían impuesto sus responsables.

Esta intuición se ve reforzada cuando descendemos al estudio de casos singulares de los que se conserva una importante masa documental que permite reconstruir con gran detalle el proceso de organización y evolución de una de estas unidades hasta el mismo momento de su disolución en FET y de las JONS. Los fondos custodiados en la antigua Comisaría de Investigación y Vigilancia de Ourense nos han permitido acceder a varios cientos de informes de conducta de milicianos de segunda línea, muchos de ellos relacionados, precisamente, con ese proceso de depuración al que

\footnotetext{
${ }^{27}$ El Pueblo Gallego, 12/09/1936, p. 3.

${ }^{28}$ Cit. en SEVILLANO CALERO, Francisco, Exterminio..., op. cit., p. 49.
} 
aludíamos. A partir del cruce de diversas fuentes hemos podido identificar a un total de 1.204 afiliados y aspirantes domiciliados en el municipio de Ourense. El número de informes de conducta a los que aludíamos asciende a 1.018, remitidos por la Comisaría a la Comandancia del Batallón y al Gobierno Civil; un pequeño número también acabó incorporándose a varios sumarios instruidos contra caballeros por los jueces militares de la plaza. Dichos informes contienen información sobre aspectos muy variados, que van desde la actuación política y social — pertenencia a partidos políticos y organizaciones sindicales, participación en manifestaciones, asistencia a mítines, conducta religiosa, etc. - a la vida económica, familiar y privada - actividad profesional, estado civil, relaciones con la esposa y los hijos, comportamiento público, lugares de ocio, etc. - de los interesados. Se trata, lógicamente, de una masa documental muy desigual, puesto que la mayor parte de los expedientes relativos a "personas de orden" y elementos "apolíticos" se despachan en varias líneas; en cambio, los que se refieren a sujetos comprometidos con organizaciones republicanas y obreras contienen, en general, una información mucho más rica.

La fiabilidad de este tipo de fuentes — los informes de conducta - para determinar la filiación política y/o sindical de los investigados suscita no pocas reservas entre los historiadores. Algo que resulta perfectamente lógico teniendo en cuenta la acusada tendencia de las diferentes instancias represivas del régimen a identificar a todos los colectivos republicanos con el marxismo e, incluso, con el comunismo; por no hablar de las tergiversaciones y lecturas interesadas de hechos y sucesos que contienen con frecuencia. Los informes que manejamos no son inmunes a estos vicios, pero, en lo tocante a la procedencia política y sindical, resultan muy exactos por el modo en que fueron elaborados: cuando la instancia solicitante remitía un listado con los individuos de los que se solicitaba información, los funcionarios policiales anotaban el número de expediente que figuraba en sus ficheros y, a continuación, se contrastaban los nombres con el libro-registro de afiliados que, suponemos, era copia del que se llevaba preceptivamente en el Gobierno Civil. Algunos incluso escribían directamente la filiación sobre las listas, lo que los convierte en mucho más fiables que los cursados, por ejemplo, por los puestos de la Guardia Civil, que no siempre disponían de estos registros.

La secuencia temporal con la que estos informes fueron demandados pone de manifiesto algo fácilmente imaginable en función de la rapidez con la que fueron organizadas las tres primeras compañías de Caballeros: como en toda la España rebelde, los factores propagandísticos y la necesidad de mantener la salvaguarda del orden en la retaguardia prevalecieron inicialmente sobre el filtrado ideológico y la depuración social y política de sus afiliados. Sólo cuando aquélla estuvo asegurada y el proceso de institucionalización del régimen empezaba a dar sus primeros pasos, la purga y el saneamiento se llevaron a cabo de forma más metódica y sistemática y el tamiz se hizo más fino para que sólo quienes acreditasen un pasado impoluto - o casi- pudieran continuar prestando servicios en la milicia.

De hecho, el alto mando militar no tardó en ser consciente de que muchos izquierdistas intentaban utilizar estas organizaciones de segunda línea como una especie de paraguas protector frente a la furia represiva desatada y temían — en verdad fundada- 
mente- la progresiva infiltración de elementos de dudosa lealtad. Así, en la segunda quincena de septiembre de 1936, los responsables de la $8^{\text {a }}$ División remitieron un escrito a todas las Comandancias Militares de las cuatro provincias galegas en el que hacían referencia a las

(...) condiciones que ha ( $\mathrm{sic}$ ) de reunir todos los Srs. que formen parte de las Milicias Ciudadanas armadas para cuyo ingreso han de tenerse en cuenta los antecedentes político-sociales, conducta - vicios - tendencias, concepto que merece en el pueblo y si está emparentado con personas que hayan tenido actividades políticas de carácter extremista $^{29}$.

A resultas de estas instrucciones se crearon diversas comisiones depuradoras encargadas de centralizar todos los trabajos de investigación. En el caso de Ourense, sus primeros informes - los referidos a los meses comprendidos entre septiembre y noviembre de 1936 - confirmaron los temores del alto mando castrense: más de la mitad de ellos (concretamente el 50,98\%) se referían a solicitudes formuladas por individuos que habían tenido algún compromiso político o sindical con la República. Entre éstos, los considerados propiamente "republicanos" representaban el 42,31\%, seguidos de socialistas y de los calificados de "acomodaticios" sin filiación determinada (un 19,23\% cada uno) y comunistas y galleguistas (ambos con el 7,69\%). Los restantes incluyen a los considerados genéricamente "de buena conducta" (de los cuales el $76 \%$ son identificados como afectos y no militantes en ninguna organización del Frente Popular, mientras el otro $24 \%$ son personas de probada solvencia moral, de las que no se conocen tratos con elementos izquierdistas, que adoptaron inicialmente una actitud pasiva). Sin duda estos resultados ayudan a explicar por qué a partir del mes de diciembre comienza a realizarse una investigación mucho más exhaustiva sobre los alistados de primera hora — que momentáneamente habían quedado a salvo de las pesquisas de la Comisión, al trabajar ésta sobre las incorporaciones producidas con posterioridad al envío del mencionado oficio de la División- y sobre los que se van incorporando en sucesivas remesas.

El resultado final de tales pesquisas nos conduce a destacar como aspecto más significativo el carácter de milicia-refugio que las unidades de segunda línea tuvieron para numerosos comprometidos con organizaciones obreras y republicanas en puestos de simple militancia e, incluso, en la dirección de alguna de las organizaciones sindicales integradas en la Casa del Pueblo ourensana. Nada menos que un 22,59\% de los aspirantes a caballeros y milicianos de segunda línea pueden incluirse dentro de esta categoría; una cifra que adquiere su verdadera significación si tenemos en cuenta que los directivos más activos y radicales ya habían sido eliminados físicamente, estaban detenidos o habían logrado huir. Los identificados como "republicanos" constituyen el grupo más numeroso con un total de noventa casos (el 8,84\% del total de los 1.018 informes encontrados), seguidos por "acomodaticios" (cincuenta y nueve casos y $5,80 \%$ del total) y por socialistas (cincuenta y un casos y $5,01 \%$ ). A mucha

\footnotetext{
${ }^{29}$ ACO, expediente 102.784 .
} 
distancia están los afiliados al PCE (diecisiete casos y 1,67\%) y al Partido Galeguista (once casos y $1,08 \%$ ).

Los dos únicos miembros de CNT representan un simbólico 0,20\% de las solicitudes, al igual que el solitario masón conocido encartado en la causa 155/1937 por su pertenencia a la logia Constancia $n^{\circ} 13$, cuyo informe de conducta no se conserva, pero sí aparece su nombre en los listados de afiliados publicados por el diario $L a$ Región. El hecho de que la abundante documentación encontrada en el domicilio del "venerable maestro" Abdón Vide Villanueva no tardara en hacerse pública acompañada del correspondiente listado de afiliados, pudo actuar como elemento disuasorio para que los masones de la vieja Auria no intentaran siquiera solicitar su admisión en la milicia. De todas formas, esta consideración no resulta de todo convincente a juzgar por la actitud de conocidos militantes de izquierda de compromiso mucho más notorio que el de estos hombres. ¿A lo mejor el prurito de negarse a figurar en las listas de los colaboradores del, para ellos, régimen clerical-fascista que con tanta saña perseguía todo lo que sonara a democracia y librepensamiento? ¿Quizás el haber optado por esconderse o, simplemente, el deseo de pasar por completo desapercibidos con la esperanza de no ser alcanzados por la furia represora? Lo que resulta innegable, en todo caso, es que los masones ourensanos no fueron tan proclives como sus hermanos pontevedreses y coruñeses a la hora de procurar con su ingreso en las milicias de segunda línea una fórmula de salvación para la sus personas y sus haciendas

Estos porcentajes guardan, sin duda, notables paralelismos con el nivel de militancia de las diferentes organizaciones políticas de la capital ourensana; pero también son coherentes con el grado de compromiso ideológico de cada una de ellas. No cabe duda que los republicanos procedentes del Partido Republicano Radical (PRR) -el cual se hizo con buena parte de las antiguas redes clientelares de la Monarquía- o del Centro Portelista — que, a su vez, captó a un número significativo de los acólitos del anterior cuando ya se encontraba en pleno proceso de desintegración- tenían motivos para pensar que su pasado podría lavarse con facilidad comprometiéndose activamente con las milicias; nada descabellado a juzgar por el hecho de que el mismísimo organizador y comandante del Batallón, el ya citado A. Casar, había figurado en las listas lerrouxistas al lado de alguno de los solicitantes.

Los que habían sido miembros de Izquierda Republicana (IR) o de Unión Republicana (UR), por su integración en las candidaturas del Frente Popular, se sabían en no tan favorable situación para superar el escrutinio. Ahora bien, siempre que se tratase de meros afiliados y que no se hubiese destacado en manifestaciones ni intervenido en debates, era posible argumentar que la militancia había venido impuesta más por una necesidad laboral, por un compromiso de familia o de relaciones personales o por alguna deuda contraída que por un auténtico compromiso ideológico. De hecho, este es el argumento recurrente de los considerados "acomodaticios", que incluyen a un amplio espectro de individuos de los que se dice simpatizaban con tal o cual partido republicano por agradar a un dirigente, obtener un favor, conservar un puesto de trabajo o desempeñar un cargo concreto. Aunque los informes policiales los consideran "poco recomendables", también no dejan de poner de manifiesto su buena conducta pública y privada, su nula peligrosidad y, salvo excepciones, el satisfactorio 
cumplimiento de sus obligaciones religiosas y familiares y su contribución a alguna de las numerosas suscripciones patrióticas abiertas. Por otro lado, no cabe olvidar que un porcentaje nada despreciable de los "republicanos de izquierda" eran personas de una notable significación social (comerciantes, industriales, funcionarios medios y altos, algunos propietarios y rentistas, etc.) capaces de movilizar influencias en su favor y con una extensa red relacional en la que no faltaban personajes que ocupaban puestos destacados en la estructura de poder creada por los rebeldes.

En cambio, los afiliados a partidos obreros eran plenamente conscientes de que el simple hecho de figurar entre los adheridos a las milicias no era, en absoluto, garantía suficiente para, en el mejor de los casos, no ser objeto de alguna sanción económica o administrativa. Además, cuanto más notorio hubiese sido su compromiso anterior, mayores eran las posibilidades de encontrarse reclamado en alguno de los centenares de sumarios abiertos por las más diversas jurisdicciones y autoridades. No parecía aconsejable, por tanto, llamar la atención sobre su situación tentando a la suerte con una solicitud que, más pronto que tarde, implicaba recabar información de toda una serie de instancias inquisitoriales destinadas a informar sobre su conducta.

Por último, el escaso número de los galleguistas está claramente en relación tanto con su reducido nivel de militancia como con la escisión padecida en víspera de las elecciones de febrero en la provincia: su ala más derechista había optado entonces por no integrarse en las candidaturas del Frente Popular y abandonar el partido; en la nueva coyuntura política, la mayoría de los escindidos optó por un prudente silencio mientras otros no se recataban de proclamar a los cuatro vientos su compromiso, siquiera apócrifo, con el nuevo régimen. El minoritario sector izquierdista, que compartió listas y tribunas en las elecciones legislativas y de compromisarios con "republicanos avanzados", socialistas y comunistas, fue tan perseguido como éstos últimos, pues a su condición de "izquierdistas" unían la de "separatistas"; dos pecados demasiado graves como para esperar la más mínima clemencia por parte de los sublevados.

Un caso especial lo representan los treinta y cinco individuos $(3,44 \%$ del total $)$ considerados "indeseables" Se trata de un grupo relativamente importante en el que se incluyen toda una serie de casos que tienen en común hacer referencia a personas de una conducta social viciada (carteristas, malhechores, delincuentes, proxenetas...) que, además, carecían de un compromiso político anterior. Todo indica que para ellos el ingreso en la milicia se presenta, fundamentalmente, como un mecanismo para acceder a una serie de elementos diferenciadores - uniforme, arma...- que en otro caso les estarían vedados. Incluso no es descartable que algunos lo vieran como una forma de garantizar la subsistencia al menos los días de prestación de servicio, ya que, en ocasiones, se le entregaban a los milicianos vales para la cena o la comida.

Finalmente hay que referirse al grupo de los clasificados como de «buena conducta». Dentro de estos sorprende el escaso número de los militantes en partidos de derechas durante la República: un pírrico 2,36\% del total y veinticuatro casos computados. A nuestro juicio, este hecho está relacionado con la notoriedad pública de algunos individuos que ingresaron en las milicias de los que los mandos militares ya no solicitaban informes, como parecen demostrar los cerca de un centenar de indivi- 
duos de conocida militancia en Acción Popular Agraria - el grupo que proporciona el mayor número de adheridos dentro de los afiliados de derechas-, en las Juventudes de Acción Popular y en Renovación Española, de los que sólo en una escasa cuarta parte se piden informes. La mayoría, en efecto, fueron despachados con el lacónico "no pertenecían a ninguna de las organizaciones ni partidos afectos al Frente Popular y están considerados como afectos al Movimiento", que en su conjunto suponen el $44,20 \%$ del total (450 casos registrados). Naturalmente en este segmento se encuentran los que, llevados por el fervor patriótico desatado por la guerra y por sus convicciones ideológicas anteriores, se suman en masa a las milicias deseando hacer ostensible su compromiso con los principios que inspiran al nuevo régimen y colaborar en la persecución de los disidentes.

El grupo de los clasificados como "pasivos" incluye a aquellos individuos que en los informes aparecen bajo expresiones del siguiente tenor: "al iniciarse el G.M.N. mantuvo una actitud pasiva", "está considerado como apolítico", "en política se mostró siempre indiferente", y aquéllos para los que se emplean los calificativos de "neutro" y "tibio". Cuantitativamente su peso es muy elevado: el 26,72\% del total (272 casos) e incluso pensamos que se encuentra infravalorado en beneficio de los considerados como "afectos", a juzgar por el hecho de que listados que contienen varias docenas de individuos se liquidan con la expresión antes señalada, mientras que los informes relativos al sector que nos ocupa son mucho más individualizados. En todo caso este es el grupo en el que resulta más difícil de interpretar la decisión de comprometerse con las milicias por la confluencia de múltiples factores que se relacionan tanto con la situación personal o con las expectativas individuales de cada individuo como con el ambiente opresivo creado por el franquismo, para el que pasivos e indiferentes eran, en principio, difícilmente tolerados.

No faltan tampoco representantes de ese sector para el que el lucimiento de un uniforme, la exhibición de un arma o el acceso a un espacio de sociabilidad diferenciado de sus "iguales" representa la culminación de unas expectativas vitales que los llevan a integrarse en una organización en la que lo de menos es la orientación ideológica. No hay que olvidar que entre los propios apologistas del régimen este aparente "igualitarismo" era algo resaltado incluso por quienes se convirtieron en sus cronistas: M. Silva Ferreiro, al referirse al amplio espectro profesional representado entre los caballeros, afirmaba a pie de página que "no era raro el caso de ver a un obrero, que era clase en el batallón, mandar a personas distinguidas del pueblo" ${ }^{30}$. ¿Había acaso mejor prueba de los ideales redentores y de la hermandad entre las clases que inspiraba el Movimiento?

${ }^{30}$ SILVA FERreIRO, Manuel: Galicia y el Movimiento Nacional. Páginas Históricas, Santiago, Imprenta y Enc. del Seminario Conciliar, 1938, p. 448. 


\section{Conclusión}

Las milicias de segunda línea y, en particular, los cívicos, constituyeron un buen ejemplo de la capacidad organizativa del bando rebelde y de su intento de encuadrar a las masas que les apoyaban en una estructura disciplinada, jerárquica y militarizada que no tardó en demostrar su gran operatividad en varios ámbitos. El primero, para publicitar y magnificar ante los ciudadanos los apoyos sociales que tuvo el golpe de Estado en la España rebelde, contribuyendo a esa mística patriótica que daba la sensación de que todo lo inundaba. El segundo, desde el punto de vista de la generación de lealtades compulsivas entre sectores sociales menos dispuestos a la movilización en su favor, pero que tampoco deseaban oponérsele frontalmente. El tercero, sobre todo en esos momentos trascendentales en que la suerte de las armas y el destino del golpe más inciertos parecían, a la hora de colaborar en el sometimiento de los más o menos activos núcleos de resistencia que se produjeron en buena parte de la geografía sublevada y que, más pronto que tarde, fueron sometidos sin contemplaciones. En definitiva, todo aquello que las envolvía (desfiles, concentraciones, mítines, presencia en misas y procesiones, exhibición del uniforme, ejecuciones - cuando tomaron parte activa en ellas-...) contribuyó eficazmente al reforzamiento de las identidades propias y a la estigmatización del enemigo ${ }^{31}$.

Dominados éstos, resultaron decisivas para afianzar el control de una retaguardia que no resultó tan "segura", "entusiasta" y "leal" como daban a entender los panegiristas del régimen, los mismos que excitaban a una eficaz purga que extirpase de raíz y para siempre toda esa "canalla" que sólo esperaba un revés de las invictas armas nacionales para ejecutar su venganza. De este modo, ejercieron un efecto paralizador y disuasorio de cualquier intento de oposición - y aun de indisciplina - de los desafectos, que permitió enviar a los frentes de guerra a milicianos y soldados jóvenes con los que nutrir los ejércitos rebeldes sin necesidad de desperdiciarlos en tareas de mantenimiento del orden. Una acción paralizante a la que no fue ajena, en algunos casos, su participación en la represión paralegal y su papel como privilegiados informadores de la conducta de sus vecinos sospechosos, actuando así de "prolongación de los oídos, ojos y boca del mando", como rezaba el reglamento de la Defensa Ciudadana de Badajoz.

Las milicias de segunda línea también se convirtieron en abrigadero, no siempre excesivamente seguro, para viejos comprometidos con la República que buscaban en ellas amparo y protección frente a la persecución desatada; para quienes no parecían tener otra opción que la de peregrinar de un lado a otro "...buscando seguro refugio, dadas las actuales circunstancias" 32 . Algo perfectamente lógico cuando desde el mismo momento en que el golpe degenera en guerra civil, en toda la retaguardia rebelde

${ }^{31}$ Cfr. CRUZ, Rafael: «Las campañas rebeldes de aniquilación del enemigo», en Ayer, 76 (2009), p. 75. La cuestión del reforzamiento de las identidades en el bando rebelde también se encuentra extensamente desarrollada en NÚÑEZ SEIXAS, Xosé Manoel: ;Fuera el invasor! Nacionalismo y movilización bélica en la Guerra Civil española, Madrid, Marcial Pons, 2006, pp. 177 y ss.

${ }^{32}$ Informe relativo a O.L.F, en ACO, expediente 102.784. 
y en cualquiera de las milicias que se formaron, se quiso primar el número sobre la "calidad" del compromiso.

A lado de aquéllos, también encontraron acomodo individuos deseosos de medrar delatando a antiguos izquierdistas, buscando congraciarse con las autoridades o, simplemente, liquidar viejas cuentas que las circunstancias les permitían reclamar. En otros casos sus insignias y uniformes fueron utilizados para imponer auténticas estructuras de dominación en los pequeños pueblos y aldeas en circunstancias en las que un arma y una camisa daban acceso a toda una serie de prebendas y privilegios que podían obtenerse por la fuerza o de buen grado de los sufridos vecinos. No faltaron, en fin, ejemplos en los que estos mismos cívicos se enfrentaron al imperio del terror desatado por falangistas y/o requetés que actuaban sin freno alguno, consiguiendo limitar sus desmanes; y de otros en los que los tradicionales muñidores de la política local encontraron en ellos el mejor instrumento para seguir controlando vidas y haciendas. Nada tiene de extraño que se multiplicasen los conflictos entre las distintas unidades de voluntarios por toda la retaguardia, los cuales, como hemos destacado en otro lugar, fueron un elemento determinante para su forzada unificación a través del Decreto de 19 de abril de 1937 que significó su final como unidades autónomas y su inclusión en el conglomerado de FET y de las JONS ${ }^{33}$.

En esta multiplicidad de orígenes y de roles, de móviles y de intenciones, es donde reside la complejidad analítica de estas organizaciones, las milicias de segunda línea. Unas unidades en cuyos linderos orden público y represión, búsqueda de legitimación y de seguridad, se entremezclan al servicio de una estrategia de dominación que buscaba, en última instancia, encuadrar a los simpatizantes, atraerse el apoyo de indiferentes, pasivos y no comprometidos y paralizar a los disidentes y hostiles haciéndoles ver lo inútil de cualquier manifestación de resistencia.

${ }^{33}$ PRADA RODRÍGUEZ, Julio, “ 'Que jamás la sangre derramada sirva para florecer partidos políticos'. El nacimiento de FET y de las JONS en Ourense", Espacio, Tiempo y Forma, T. XV, (2002), pp. 422 y ss. 